\title{
What's the Buzz? How to Build a Word-Of-Mouth Campaign in 2012
}

\section{Elizabeth Thomas*}

Lecturer, Murray State University, USA

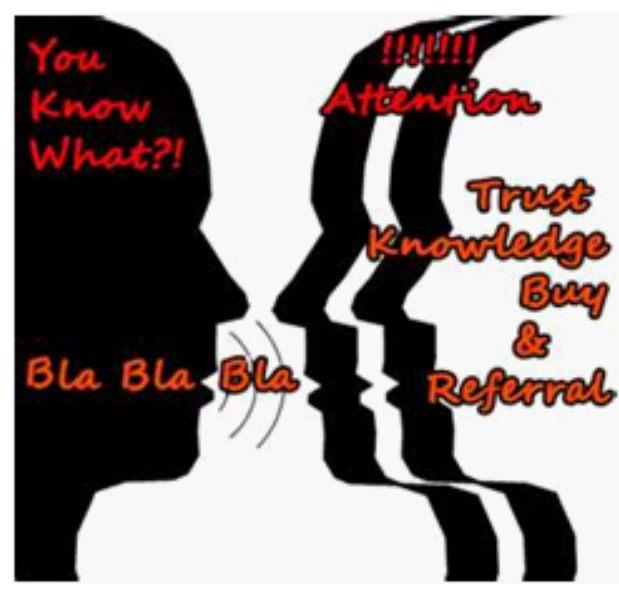

Word-of-mouth advertising is still the very best kind of advertising. Marketers have known this for decades, but social media has created so many new ways to get people talking - or buzzing - about products and services that many are scrambling to keep up. Buzz can be simply defined as "any person-to-person conversation about someone or something."

Producing a great product is the first, best way to generate positive "buzz," but even happy customers forget about products over time. Starting the conversation rolling or re-rolling often requires a trigger - an event, item or idea - to get people talking.

\section{Experience-based versus secondhand buzz}

There is a big difference between the kind of buzz people get from someone who owns or uses a product and the kind they get secondhand, from someone who has "heard" something about the product. This is not to say that you can't get great buzz secondhand. However, as much as $30 \%$ of negative word of mouth is generated by people who have never used the product or service. It's this "he said, she said" that most often carries serious negative consequences. It also affords opportunities to marketers who are quick to respond and who really "listen" to the buzz they generate.

\section{Buzz is being spread in new ways}

Big brands, like Purina, Ford, WholeFoods, Comcast, IBM, Dell, Southwest Airlines and many others have established a strong presence on social networking sites like Twitter and Facebook where consumers are spending more and more of their time. In fact, Facebook's membership just passed the 800 million mark (that's more than double the population of the U.S.) and Twitter is closing in on 200 million users. That's a huge number of potential customers talking about items they use and brands they love -- every day.

According to a recent Reuter's article, even Hollywood is increasingly relying on Twitter and Facebook to gauge the popular buzz of films before they premiere. This change reflects the power of average filmgoers over the once-mighty film critics. Studio execs are starting to track the instant reactions of ordinary people to their new offerings. Several companies have sprung up to provide tools that monitor and analyze the buzz on social networking sites. Buzz for them equals the amount of chatter or interest in a movie, which can help drive box office sales.

In the past, studios relied heavily on focus groups, audience surveys and reviews by film critics to anticipate how a film would fare at the box office. Recent activity has underscored the influence of online word-ofmouth in a world where one Twitter comment can help make or break a movie.

Neilson Online Digital Strategies is one of the companies making the most of buzz. Executives there say the writing is on the wall for films quicker than before. If they know a film won't do well, they may decide not to spend the entire marketing budget. Sometimes, the studio saves its marketing dollars for the DVD, simply based on Twitter and Facebook buzz reports.

Online buzz drove the film "Paranormal Activity" to a $\$ 7.9$ million box office in the U.S. and Canada earlier this year, setting a record for a movie playing in less than 200 theaters. The low budget horror flick got on its way to wider release thanks to a buzz campaign.

According to Neilson, most commentary about products (approximately 74\%) is still spread the old-fashioned way - through person-to-person, face-to-face communication. All the current attention on buzz marketing may seem like overkill, but savvy marketers know that new media and technology have changed the marketing playing field. Product managers can no longer afford to ignore negative online reviews of products or the angry tirades of bloggers who have had a bad experience.

As we entered this new millennium, several companies began to develop tools to analyze online buzz, even though only about 10 percent of buzz was actually happening online. Companies like Cymfony, MotiveQuest, Neilsen Online and BuzzMetrics were quick to create the initial software. They searched the internet for keywords about brands and analyzed the conversation surrounding the material. Soon, they found that measuring online buzz helps with sales forecasting.

\section{Listening with our eyes}

Proctor \& Gamble's Tremor Division offers a number of lessons. The main idea: Listen, listen and then listen (to your customers) some more. The most important part of buzz marketing is dealing with social networks - it is not about us. It's about them. We shouldn't just listen twice as much as we talk (or "post"), we should listen 10 times as much.

*Corresponding author: Elizabeth Thomas, Murray State University, USA, Tel: (270) 809-5441; E-mail: ethomas@murraystate.edu

Received January 16, 2012; Accepted January 16, 2012; Published January 18 2012

Citation: Thomas E (2012) What's the Buzz? How to Build a Word-Of-Mouth Campaign in 2012. J Mass Communicat Journalism 2:e112. doi:10.4172/2165-7912.1000e112

Copyright: ( $) 2012$ Thomas E. This is an open-access article distributed under the terms of the Creative Commons Attribution License, which permits unrestricted use, distribution, and reproduction in any medium, provided the original author and source are credited. 
A clever buzz marketer is also an investigator, finding out what people are concerned about, what information and solutions they are looking for, and what products they are talking about. Then, he or she can tailor online communities, conversations and promotions to get vocal consumers talking. Listening to the current buzz is likely to provide companies with valuable insights into what they are doing right and wrong, where they should be headed and what the market wants.

Within any social network there is a certain degree of "homophily," which means that similar people are attracted to each other. It's the same in marketing. Certain products and services are attractive to people who find similarities in the product itself or the way it is marketed.

While a product may be accepted within one group of people, it may be equally rejected by another -- despite sharing a close relation. Once a product enters a "cluster," information about that product moves smoothly from person-to-person. Then, a numbing effect often sets in. No one within the cluster feels the need to talk about that particular subject with anyone outside.

\section{Accelerating Buzz}

We know that people love to talk. The key to spreading buzz is very often finding links between a variety of different networks. If a company can disperse buzz across diverse groups, it may generate enough momentum that it gains virility, and with some luck, takes on a life of its own. In most social networks, each person has an individual voice and a sphere of influence. Sending a message or sparking buzz with enough different networks can give a product, company or brand a voice. The key to buzz marketing is finding a way into these social networks and stimulating the communications contagion. Sometimes, it takes a giant push from the marketing team to get the buzz going.

\section{Pushing the envelope}

Public relations, advertising and marketing are about getting attention; anything that's new, different or innovative has a good chance of gaining some. Problems arise when that fresh idea crosses a line outside of what most community members consider acceptable. The problem is simple: the more people there are in a community, the more opinions there are about whether a line has been crossed or not. The best way for companies to avoid this trouble is by steering clear of "undercover" or stealth marketing. When consumers find out that advice or information they are receiving is secretly aimed at selling them something, they find the practice offensive.

When marketers try to predict future success based on buzz it is crucial to measure the dispersion of the message. If buzz comes from only one cluster, then chances are the product didn't attract as many people as the marketers thought. It is important to keep in mind that word-of-mouth can spread at different speeds. A good tactic is to attract multiple clusters by "seeding."This means giving the product to people in different clusters in order to stimulate a discussion that spreads throughout networks.

\section{Participation is all-important}

Another key is encouraging participation. Inviting consumers to participate in the process of creating a product or pre-testing it creates a sense of empowerment. People who are directly involved with a product are more likely to talk about it. Such interaction between the company and customers keeps people involved and leads to better products more people hear about.

Buzz requires constant fuel. Sneak previews are a good method for keeping up interest. Information revealed must not be common knowledge, however. People buzz about things they suspect others don't know; they want to be the only ones with the information so that sharing it makes them feel special.

\section{Mass media advertising still matters}

Mass media substitutes such as Internet television and the everpopular DVR (digital video recorder) allow users to watch their favorite programming, commercial-free. Although this poses a larger problem for advertisers, product placement is increasing in an effort to keep mass media advertising profitable and a still worthwhile venture.

A good advertisement can stimulate buzz in several ways. First, it can provide a jump-start as in the case of the new Microsoft OS (operating system), Windows 7. Advertisements also generate buzz when they become reference points for consumers. The Keller Fay group found that 21 percent of product-oriented conversations used a product's advertisement as a type of validation to their statements such as "I saw it in a commercial."

\section{Four rules for incorporating buzz}

1. Keep it simple: Advertisements such as DeBeers "Diamonds are forever" are effective because they use the simple approach.

2. Tell us what's new: Customers are not likely to pass on information that sounds cliché. In order to separate themselves from these kinds of ads, marketers need to let the customer know what's different.

3. Don't make unsupported claims: Honesty is the best policy when it comes to advertising. Companies don't want to lose credibility. In fact, the FTC (Federal Trade Commission) has recently settled a claim against the makers of Airborne, a tablet marketed as a cold prevention and treatment remedy. The makers of the drug now owe the FTC \$30 million for not having enough evidence to support claims.

4. Ask people to state what is special about a product: If customers can't differentiate the product from its competitors, they won't be able to buzz about it.

\section{What's the Buzz}

To ensure that a product, brand or company can generate and monitor the elements of buzz, just consider this series of simple questions. 1) Do you have the right product? 2) Does it enhance the lives of the people who use it? 3) Are there opportunities to create a "Wow" effect? 4) Is the product visible and can it be made more so? 5) Is something new being offered? 6) And, is the product ready?

Generating buzz means employing the right approach. It also means listening to the buzz that already exists by talking to consumers, identifying network hubs, and considering the many possible techniques for building effective buzz. The more people a company can engage in conversation, the more effective the effort. Advertising campaigns can also build buzz, and resellers can play a major role in spreading the word about products and campaigns. Since buzz is all about newness, maintaining it presents the greatest challenge.

With proper planning, the right product and a dash of genius, it is possible to put a product into more minds, more conversations and more purchases. 